\title{
Propriedades Antioxidantes e Efeitos Antimicrobianos da Kombucha: Revisão da Evidência Científica
}

\author{
Gislane Romano Mendonça, ${ }^{1}$ Ana Lúcia Fernandes Pereira, ${ }^{2}$ \\ Adriana Gomes Nogueira Ferreira, ${ }^{1}$ Marcelino Santos Neto, ${ }^{1}$ \\ Richard Pereira Dutra, ${ }^{1}$ Virgínia Kelly Gonçalves Abreu ${ }^{1}$
}

\begin{abstract}
RESUMO
A kombucha é uma bebida produzida a partir da fermentação de chás por culturas simbióticas de bactérias e leveduras. Esta bebida ganhou popularidade em razão dos seus benefícios à saúde e por suas propriedades antioxidantes, que podem ser maiores que o das infusões não fermentadas. A kombucha também apresenta atividade antibacteriana contra bactérias Gram-positivas e Gram-negativas patogênicas, sendo o principal componente antibacteriano o ácido acético. Além disso, apresenta propriedades anticâncer, antidiabética, anti-inflamatória, hepatoprotetora e desintoxicante. Assim, o objetivo desta revisão integrativa é analisar a produção científica sobre as propriedades antioxidantes e os efeitos antimicrobianos de kombuchas. A revisão integrativa foi baseada em etapas sistemáticas, nas bases de dados Scopus e ScienceDirect. As buscas seguiram os critérios de inclusão: estudos que abordaram as propriedades antioxidantes e antimicrobianas da kombucha, disponíveis na íntegra nos idiomas inglês, português e espanhol, sem período de publicação delimitado. Excluídos: teses, dissertações, revisões (sistemática, narrativa e integrativa), artigos de opinião e editoriais. Foram incluídos 18 artigos, e 7 deles analisaram a atividade antibacteriana e observaram que as kombuchas apresentam efeitos maiores que as infusões não fermentadas. A maioria dos artigos determinaram a atividade antioxidante de kombuchas de diferentes substratos, principalmente do chá verde e do chá preto. Todos os artigos mostraram aumento da atividade antioxidante das kombuchas ao longo da fermentação. Assim, a kombucha pode ser uma alternativa saudável para a manutenção dos níveis de radicais livres e no combate de micro-organismos patogênicos para quem a consome.
\end{abstract}

Palavras-chave: Chá de kombuchas. Atividade antioxidante. Atividade antimicrobiana.

ANTIOXIDANT PROPERTIES AND ANTIMICROBIAL EFFECTS OF KOMBUCHA: REVIEW OF SCIENTIFIC EVIDENCE

\section{ABSTRACT}

Kombucha is a beverage produced from the fermentation of teas by symbiotic cultures of bacteria and yeasts. This beverage gained popularity due to its health benefits and its antioxidant properties that may be greater than that of unfermented infusions. Kombucha also has antibacterial activity against pathogenic Gram-positive and Gram-negative bacteria, with the main antibacterial component being acetic acid. Moreover, it has anti-cancer, anti-diabetic, anti-inflammatory, hepatoprotective and detoxifying properties. Thus, the aim of this integrative review is to evaluate scientific production on the antioxidant properties and antimicrobial effects of kombuchas. The integrative review was based on systematic steps, in the Scopus and ScienceDirect databases. The searches followed the inclusion criteria: studies that addressed the antioxidant and antimicrobial properties of kombucha, available in full in english, portuguese and spanish, with no limited publication period. Excluded: theses, dissertations, reviews (systematic, narrative and integrative), opinion articles and editorials. 18 articles were included, 7 articles determined antibacterial activity and observed that kombuchas have greater effects than unfermented infusions. Most articles determined the antioxidant activity of kombuchas from different substrates, mainly green and black teas. All articles showed an increase in the antioxidant activity of kombuchas during fermentation. Thus, kombucha can be a healthy alternative for maintaining levels of free radicals and fighting pathogenic microorganisms for those who consume it. Keywords: Kombucha tea. Antioxidant activity Antimicrobial activity.

RECEBIDO EM: 8/4/2020

MODIFICAÇÕES SOLICITADAS EM:19/5/2020

ACEITO EM: 30/5/2020

\footnotetext{
Universidade Federal do Maranhão (Ufma). São Luiz/MA, Brasil.

${ }^{2}$ Autora correspondente. Universidade Federal do Maranhão (Ufma). Av. da Universidade, S/N, Bairro Dom Afonso Felipe Gregory, Imperatriz/MA, Brasil. CEP 65914-535. http://lattes.cnpq.br/7841826430721579. http://orcid.org/0000-0001-6562-252X. anafernandesp@gmail.com
} 


\section{INTRODUÇÃO}

O processo de fermentação é um método antigo para preservação de alimentos, sendo também um sistema de conservação de energia de baixo custo, essencial para garantir a vida e a segurança dos alimentos. Recentemente, este bioprocesso foi aplicado para a produção e extração de compostos bioativos de plantas em indústrias de alimentos e bebidas (VILLARREAL-SOTO et al., 2018).

Nesse contexto insere-se a kombucha, a qual consiste em uma bebida produzida a partir da fermentação de chás, geralmente os chás preto ou verde (Camellia sinensis), pelo Scoby. ${ }^{3}$ Este termo refere-se à sigla Symbiotic Culture of Bacteria and Yeast - ou, em português, Cultura Simbiótica de Bactérias e Leveduras. Para preparação de kombuchas é necessário a adição de açúcar, que consiste em substrato para a fermentação. Durante o processo, o chá começa a liberar um aroma fermentado e há formação de boIhas de gás, resultado do ácido carbônico produzido na reação. 0 tempo ideal de fermentação é de 7 a 12 dias e a temperatura de $22^{\circ}$ a $30 \circ \mathrm{C}$. Ao longo de sua fermentação ocorre um aumento da acidez em razão da produção de ácidos orgânicos (JAYABALAN et al., 2014; VILLARREAL-SOTO et al., 2018).

Esta bebida ganhou popularidade em virtude dos seus benefícios à saúde, pois ajuda a estimular sistemas glandulares, a proteger contra o diabetes, a facilitar a excreção de toxinas e a prevenir infecções (JAYABALAN et al., 2014). Além disso, estudos indicam que a kombucha pode agir como bebida probiótica, ajudando a equilibrar a microbiota intestinal, facilitando, assim, a normalização das atividades intestinais (WATAWANA et al., 2015).

Entre os efeitos benéficos do kombucha tem-se também àqueles proporcionados pelos antioxidantes. Estes protegem o organismo humano de danos causados pelo estresse oxidativo. $O$ estresse oxidativo é causado pelo acúmulo de radicais livres, e tem como consequência muitas doenças e até mesmo o enveIhecimento. A vitamina C é um dos compostos característicos de bebidas de kombucha. Este antioxidante normalmente está presente nos substratos utilizados para a produção das bebidas, tais como as folhas de chá verde e chá preto. Como um agente redutor eficaz, a vitamina $\mathrm{C}$ mostra uma poderosa propriedade de eliminação contra os radicais livres e espécies reativas de oxigênio (VITAS et al., 2013).

\footnotetext{
Uma cultura viva de aspecto gelatinoso, parecida com uma massa de panqueca, composta por bactérias e leveduras.
}

Alguns pesquisadores relataram atividades antioxidantes das bebidas fermentadas obtidas pelo kombucha no chá preto ou verde para radicais livres (BHATTACHARYA et al., 2016; CHU; CHEN, 2006). Pure e Pure (2016) reportaram que bebidas fermentadas formuladas com chá de três ervas apresentaram maior poder antioxidante que as infusões não fermentadas. As amostras fermentadas inibiram o radical livre DPPH (2,2- difenil-1-picril-hidrazil) em 92,91\%, enquanto as infusões não fermentadas inibiram em $69,93 \%$. Velićanski et al. (2014) observaram que o kombucha à base de erva-cidreira mostrou uma maior atividade antioxidante em comparação com a bebida tradicional feita a partir do chá preto.

Além da atividade antioxidante presente nas kombuchas, a bebida apresenta também uma grande atividade antibacteriana contra bactérias Gram-positivas e Gram-negativas patogênicas (VELIĆANSKI et al., 2014). O principal componente antibacteriano é o ácido acético, cuja concentração na bebida kombucha influencia diretamente seu potencial antimicrobiano. Testes com a bebida neutralizada, no entanto, apresentaram ação antibacteriana contra Staphylococcus aureus, o que indica que a atividade antibacteriana não está associada apenas à acidez, mas também a outros metabólitos biossintetizados durante o processo de fermentação (AYED; BEN ABID; HAMDI, 2017; VELIĆANSKI et al., 2014).

Com base no exposto, o objetivo desta revisão é analisar a produção científica sobre as propriedades antioxidantes e os efeitos antimicrobianos de kombucha, a fim de estabelecer uma melhor compreensão dessa bebida e seus possíveis efeitos na saúde de consumidores.

\section{MÉTODO}

Este estudo caracterizou-se como uma revisão integrativa da literatura definida como um método de revisão específica que fornece uma compreensão abrangente sobre um tema de interesse. A presente investigação utilizou as seguintes etapas: identificação do tema e elaboração da questão norteadora da pesquisa; seleção e extração dos dados; categorização dos estudos; análise dos dados; síntese dos resultados; e apresentação da revisão integrativa (WHITTEMORE; KNAFL, 2005).

A estratégia PICo foi utilizada para elaboração da questão da pesquisa, na qual " $P$ " refere-se à população do estudo (consumidores de kombucha); "I" à variável de interesse (propriedades antioxidantes e efeitos antimicrobianos) e "Co" ao contexto da pesqui- 
sa (consumo humano). Dessa forma, a questão norteadora da revisão integrativa foi: "A kombucha apresenta propriedades antioxidantes e efeitos antimicrobianos para humanos?" (SANTOS; PIMENTA; NOBRE, 2007).

A segunda etapa da revisão consistiu na busca bibliográfica nas bases de dados SciVerse Scopus e ScienceDirect (Elsevier) por meio dos Descritores em Ciências da Saúde (DeCS) no idioma inglês dos termos da língua portuguesa: "kombucha tea" combinada aos termos "antimicrobial activity" e "antioxidant activity".

Os critérios de inclusão foram: estudos que abordaram as propriedades antioxidantes e antimicrobiana da kombucha, disponíveis na íntegra nos idiomas inglês, português e espanhol, sem período de publicação delimitado. Foram excluídas teses, dissertações, revisões integrativas, narrativas e sistemáticas, artigo de opinião e editoriais.

Foram identificados 663 estudos primários. As estratégias de busca utilizadas nas bases de dados e os motivos da exclusão estão apresentados no fluxograma da Figura 1, como recomendado pelo grupo Prisma (Principais Itens para Relatar Revisões Sistemáticas e Meta-Análises). O Prisma é composto de um checklist de itens da coleta de dados e um diagrama de fluxo de seleção de artigos de quatro fases (SILVA et al., 2015).
Assim, a ferramenta utilizada para a coleta e análise dos dados contemplou os seguintes itens: título da publicação, autor(es), objetivos, ano de publicação, periódico, tipo de substrato, metodologias e resultados referentes às propriedades antioxidantes e os efeitos antimicrobianos da kombucha. Após a etapa de elegibilidade, realizou-se a coleta de dados selecionando-os de cada estudo de acordo com os objetivos da presente pesquisa.

Para o estudo das pesquisas incluídas, utilizou-se a análise de conteúdo temática. Na etapa de pré-análise foi realizada a exploração do material e tratamento dos resultados obtidos e interpretação. Nessa etapa foram organizadas as informações e a sistematização das ideias iniciais mediante a leitura dos dados, destacando elementos principais com a finalidade de identificar possíveis categorias de análise. Na segunda etapa realizou-se a exploração do material, que consistiu na codificação, classificação e agregação dos dados encontrados.

\section{RESULTADOS E DISCUSSÃO}

A partir do cruzamento dos descritores nas bases de dados, foram selecionados 39 artigos para leitura na íntegra e, ao final, 18 artigos responderam à questão norteadora. Todos os artigos estavam no idio-

Figura 1 - Fluxograma dos estudos incluídos na pesquisa

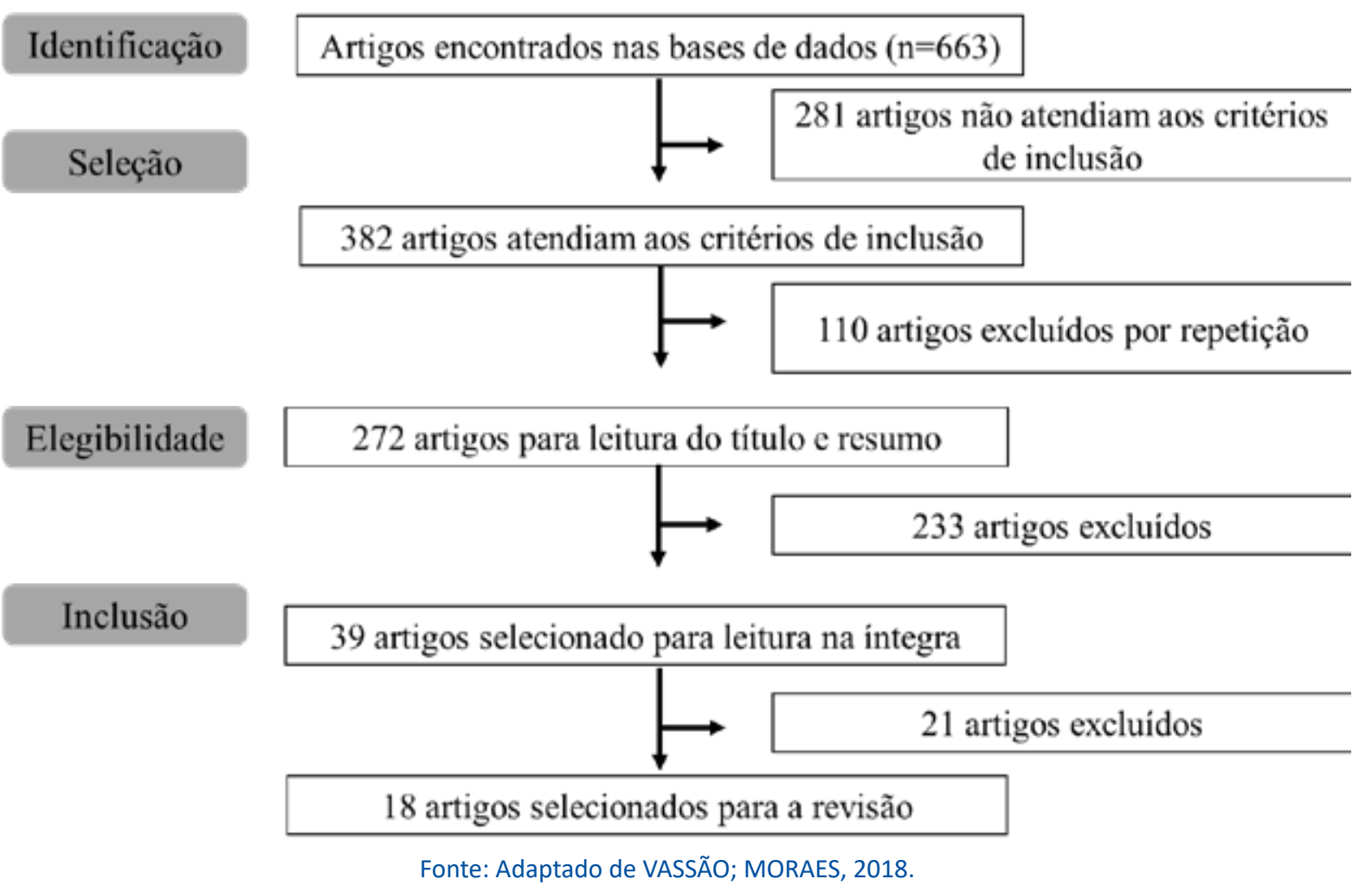


ma inglês, sendo pesquisas experimentais. Além disso, $70 \%$ são artigos publicados nos últimos cinco anos. Das publicações selecionadas para este estudo, um quadro foi desenvolvido (Quadro 1) expondo as características dessas publicações segundo o autor/ano, tipo de substrato, metodologias e resultados das atividades antioxidante e antimicrobiana das kombuchas.

Dos artigos foram coletadas as seguintes informações: 15 artigos (83\%) apresentaram resultados de atividade antioxidante, enquanto 7 pesquisas (38\%) mostraram efeito antibacteriano. As principais matérias-primas utilizadas no preparo da infusão foram o chá preto ( $53 \%$ dos artigos) e o chá verde $(53 \%$ dos artigos). Cinco estudos pesquisaram infusões preparadas com diferentes plantas, como a erva-cidreira (Melissa officinalis L.) (VELIĆANSKI et al., 2014), snake fruits (Salak Suwaru cultivar) (ZUBAIDAH et al., 2019), casca de banana (Musa sapientum) e urtiga (Urtica dioica) (PURE; PURE, 2016), suco de uva vermelha (Vitis Vinifera) (AYED; BEN ABID; HAMDI, 2017), chá branco e chá amarelo (Camellia sinensis) (GRAMZA-MICHAŁOWSKA et al., 2016).

Dentre as metodologias utilizadas nas pesquisas selecionadas para a atividade antioxidante das kombuchas, predominou em 15 artigos a técnica sequestro do radical livre estável 2,2-difenil1-picrilhidrazil (DPPH) $(83,3 \%)$. Três pesquisas $(16,6 \%)$ realizaram o método sequestro do cátion radical 2,2-azinobis-3-etilbenzotiazolina-6-ácido sulfônico (ABTS). Dos 18 artigos, $7(38,8 \%)$ avaliaram a atividade antibacteriana de kombuchas elaborados a partir de diferentes substratos, posto que 6 estudos utilizaram a técnica de formação do halo de inibição, método que verifica o tamanho do diâmetro da zona de inibição (DZI) formada pelo antibiótico, e apenas 1 artigo usou o método de concentração inibitória mínima (MIC).

Dos 18 artigos utilizados na revisão, 3 não avaliaram a atividade antioxidante das kombuchas. Os 15 artigos que determinaram a atividade antioxidante, no entanto, observaram resultados positivos quando essas bebidas foram comparadas ao chá não fermentado. Bhattacharya, Gachhui e Sil (2013) verificaram maior redução de radicais livres em kombucha de chá preto quando comparado com o chá preto não fermentado. Villarreal-Soto et al. (2019) também observaram que kombuchas de chá preto e verde têm capacidade de remoção de radicais livres superior aos dos chás antes da fermentação.

Quando avaliado o efeito de diferentes tipos de amostras, Velićanski et al. (2014) reportaram que a atividade antioxidante da kombucha de erva-cidreira apresentou resultados superiores àquelas preparadas com a amostra tradicional de chá preto. Pure e Pure (2016), por sua vez, reportaram que as kombuchas preparadas com casca de banana demonstraram atividade antioxidante superior à das bebidas fermentadas com urtiga e chá preto.

Segundo Rahmani et al. (2019), a influência da fermentação da kombucha na atividade antioxidante depende da composição microbiológica da cultura utilizada na fermentação e da composição fitoquímica do material vegetal testado. Geralmente a kombucha contém muitos compostos com atividade antioxidante, como compostos fenólicos, vitaminas solúveis em água, ácidos orgânicos e minerais (CHEN; LIU, 2000).

Nas kombuchas tradicionais, preparadas a partir de chás verdes ou pretos, a atividade antioxidante está associada à presença de compostos fenólicos, tais como ácido gálico, catequinas, ácido cafeico, rutina e ácido clorogênico. Durante a fermentação do chá, esses compostos aumentam em quantidades totais em razão da degradação de compostos maiores em compostos menores por ação de enzimas produzidas. Um exemplo dessa degradação é demonstrado pela capacidade de os micro-organismos do Scoby (Cultura Simbiótica de Bactérias e Leveduras) liberar enzimas que convertem galato de epigalocatequina e galato de epicatequina em epigalocatequina e epicatequina, respectivamente (BHATTACHARYA et al., 2016; SUN; LI; CHEN, 2015). Assim, uma vez no produto, esses compostos fenólicos facilmente doam hidrogênio hidroxil em virtude da estabilização de ressonância. Este suprimento de hidrogênio confere aos compostos fenólicos excelente capacidade de eliminação de radicais livres, tais como o DPPH (SUN; LI; CHEN, 2015).

Os dados provenientes dos estudos, portanto, evidenciaram que as kombuchas apresentam atividade de redução de radicais livres. A maioria dos artigos $(83,3 \%)$ utilizou o ensaio de DPPH, o qual é um método usado para determinar a capacidade antioxidante de substratos biológicos. A atividade de redução de radicais DPPH é uma apreciação geral sobre a percentagem de inibição dos radicais livres, previamente formados, por compostos oxidantes. É importante salientar que, embora esse método in vitro tenha vantagens, também apresenta desvantagens, como não indicarem a condição real encontrada em sistemas biológicos, uma vez que podem envolver moléculas que não existem nesses ambientes, assim como o pH do meio e a temperatura. Além disso, não se considera o metabolismo dos antioxidantes em sistemas vivos, o que poderia dar uma ideia mais real dos benefícios da kombucha para o organismo (SUN; LI; CHEN, 2015). 
Quadro 1 - Distribuição das publicações selecionadas segundo autor/ano, tipo de substrato, metodologias, resultados para a atividades antioxidante e antimicrobiana nas bases de literatura científica

\begin{tabular}{|c|c|c|c|c|}
\hline \multirow[t]{2}{*}{ Autores/ano } & \multirow[t]{2}{*}{ Tipo de substrato } & \multirow[t]{2}{*}{ Metodologias } & \multicolumn{2}{|l|}{ Resultados } \\
\hline & & & Atividade antioxidante & Efeito antimicrobiano \\
\hline $\begin{array}{l}\text { AMARASINGHE; } \\
\text { WEERAKKODY; } \\
\text { WAISUNDARA, } 2018\end{array}$ & Chá verde & $\begin{array}{l}\text { DPPH, Índice de } \\
\text { ORAC }\end{array}$ & $\begin{array}{l}\text { A eliminação de DPPH teve um aumento } \\
\text { significativo ao longo do período de } \\
\text { fermentação }\end{array}$ & $\begin{array}{l}\text { A atividade antimicrobiana } \\
\text { não foi avaliada neste } \\
\text { trabalho }\end{array}$ \\
\hline $\begin{array}{l}\text { ANSARI; POURJAFAR; } \\
\text { ESMAILPOUR, } 2017\end{array}$ & Chá verde & $\begin{array}{l}\text { Halo da zona de } \\
\text { inibição }\end{array}$ & $\begin{array}{l}\text { A atividade antioxidante não foi avaliada } \\
\text { neste trabalho }\end{array}$ & $\begin{array}{l}\text { Efeito bactericida contra } S \text {. } \\
\text { aureus e Salmonella, mas } \\
\text { não contra L. rhamnosus. O } \\
\text { chá verde não fermentado } \\
\text { não apresentou atividade } \\
\text { contras cepas avaliadas }\end{array}$ \\
\hline $\begin{array}{l}\text { AYED; BEN ABID; } \\
\text { HAMDI, } 2017\end{array}$ & Suco de uva tinta & $\begin{array}{l}\text { DPPH e ABTS, halo } \\
\text { de inibição }\end{array}$ & $\begin{array}{l}\text { Eliminação dos radicais DPPH e ABTS } \\
\text { com aumento da atividade em } 55,7 \% \text { e } \\
38,1 \% \text {, respectivamente, após seis dias de } \\
\text { fermentação }\end{array}$ & 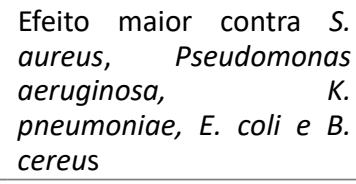 \\
\hline $\begin{array}{l}\text { BHATTACHARYA et al., } \\
2016\end{array}$ & Chá preto & $\begin{array}{l}\text { Halo de inibição, } \\
\text { MIC e MBC } \\
\text { (concentração } \\
\text { bactericida } \\
\text { mínima) }\end{array}$ & $\begin{array}{l}\text { A atividade antioxidante não foi avaliada } \\
\text { neste trabalho }\end{array}$ & $\begin{array}{l}\text { Atividades bacteriostáticas } \\
\text { e bactericidas contra todos } \\
\text { os micro-organismos } \\
\text { avaliados. A kombucha } \\
\text { com } 21 \text { dias teve maior } \\
\text { zona de inibição com } S \text {. } \\
\text { Typhimurium }\end{array}$ \\
\hline ESSAWET et al., 2014 & $\begin{array}{l}\text { Chá preto } \\
\text { enriquecido com } \\
\text { coffeeberry }^{\circledR}\end{array}$ & $\begin{array}{l}\text { Inibição dos } \\
\text { radicais hidroxila } \\
\text { e DPPH }\end{array}$ & $\begin{array}{l}\text { As atividades antioxidantes pelos radicais } \\
\text { DPPH e hidroxila aumentaram durante a } \\
\text { fermentação }\end{array}$ & $\begin{array}{l}\text { A atividade antimicrobiana } \\
\text { não foi avaliada neste } \\
\text { trabalho }\end{array}$ \\
\hline FU et al., 2014 & $\begin{array}{l}\text { Chá verde, chá } \\
\text { preto e chá em pó }\end{array}$ & $\begin{array}{l}\text { DPPH, superóxido } \\
\text { ânion e radicais } \\
\text { hidroxila e poder } \\
\text { redutor total }\end{array}$ & $\begin{array}{l}\text { As habilidades de eliminação dos radicais } \\
\text { hidroxila e DPPH foram em ordem } \\
\text { decrescente: chá verde> chá em pó> chá } \\
\text { preto. O chá preto apresentou o maior poder } \\
\text { redutor total, seguido pelo chá verde e o chá } \\
\text { em pó }\end{array}$ & $\begin{array}{l}\text { A atividade antimicrobiana } \\
\text { não foi avaliada neste } \\
\text { trabalho }\end{array}$ \\
\hline $\begin{array}{l}\text { GRAMZA-MICHA- } \\
\text { ŁOWSKA et al., } 2016\end{array}$ & $\begin{array}{l}\text { Chá branco, chá } \\
\text { verde, chá amarelo, } \\
\text { chá preto }\end{array}$ & DPPH & $\begin{array}{l}\text { Potencial de eliminação de radicais } \mathrm{DPPH} \text { : } \\
\text { chá amarelo }>\text { kombucha de chá amarelo }>\text { chá } \\
\text { verde }>\text { kombucha de chá verde }>\text { chá branco } \geq \\
\text { kombucha de chá branco }>\text { chá preto } \geq \\
\text { kombucha de chá preto }\end{array}$ & $\begin{array}{l}\text { A atividade antimicrobiana } \\
\text { não foi avaliada neste } \\
\text { trabalho }\end{array}$ \\
\hline PURE; PURE, 2016 & $\begin{array}{l}\text { Cascas de banana, } \\
\text { urtiga comum e chá } \\
\text { preto }\end{array}$ & $\begin{array}{l}\text { DPPH. Halo } \\
\text { de inibição } \\
\text { bacteriana }\end{array}$ & $\begin{array}{l}\text { A bebida fermentada dos três substratos teve } \\
\text { maior poder antioxidante do que as infusões. } \\
\text { A kombucha de casca de banana apresentou a } \\
\text { maior atividade antioxidante inibindo } 94,62 \% \\
\text { do radical DPPH }\end{array}$ & $\begin{array}{lr}\text { Nenhuma } & \text { atividade } \\
\text { antibacteriana } & \text { foi } \\
\text { observada } & \end{array}$ \\
\hline $\begin{array}{l}\text { VELIĆANSKI et al., } \\
2014\end{array}$ & $\begin{array}{l}\text { Erva-cidreira e chá } \\
\text { preto }\end{array}$ & $\begin{array}{l}\text { DPPH, atividade } \\
\text { sequestradora de } \\
\text { radicais hidroxila. } \\
\text { Halo de inibição } \\
\text { bacteriana }\end{array}$ & $\begin{array}{l}\text { A atividade de eliminação de radicais } \mathrm{OH} \text { do } \\
\text { caldo fermentado de erva-cidreira durante } \\
\text { todo o processo foi maior do que a infusão de } \\
\text { chá preto. Por outro lado, as infusões de chá } \\
\text { preto foram mais eficientes contra o radical } \\
\text { DPPH }\end{array}$ & $\begin{array}{l}\text { Reduziram o crescimento } \\
\text { de algumas bactérias } \\
\text { Gram-positivas } \quad(S \text {. } \\
\text { equorum, } S \text {. saprophyticus } \\
\text { e Bacillus sp.) }\end{array}$ \\
\hline ZUBAIDAH et al., 2019 & $\begin{array}{l}\text { Chá preto e snake } \\
\text { fruits }\end{array}$ & $\mathrm{DPPH}$ & $\begin{array}{l}\text { A atividade antioxidante da kombucha } \\
\text { tradicional foi menor que na amostra de } \\
\text { kombucha de snake fruits ao final de } 14 \text { dias } \\
\text { de fermentação }\end{array}$ & $\begin{array}{l}\text { A atividade } \\
\text { antimicrobiana não foi } \\
\text { avaliada neste trabalho }\end{array}$ \\
\hline
\end{tabular}




\begin{tabular}{|c|c|c|c|c|}
\hline $\begin{array}{l}\text { BATTIKH; BAKHROUF; } \\
\text { AMMAR, } 2012\end{array}$ & $\begin{array}{l}\text { C. sinesis, } T \text {. vulgaris } \\
\text { L. (tomilho), L. } \\
\text { citriodora (verbena } \\
\text { de limão), } R \text {. } \\
\text { officinalis (alecrim), } \\
\text { F. vulgare (erva- } \\
\text { doce) e Me. piperita } \\
\text { (hortelã pimenta) }\end{array}$ & $\begin{array}{l}\text { Atividade } \\
\text { antibacteriana por } \\
\text { ensaio difusão- } \\
\text { ágar e atividade } \\
\text { antifúngica por } \\
\text { halo de inibição }\end{array}$ & $\begin{array}{l}\text { A atividade antioxidante não foi avaliada } \\
\text { neste trabalho }\end{array}$ & $\begin{array}{l}\text { Todas as bactérias } \\
\text { testadas foram sensíveis } \\
\text { às bebidas fermentadas } \\
\text { resultantes de } C \text {. sinesis, } L \text {. } \\
\text { citriodora e Me. piperita. } \\
\text { A infusão fermentada } \\
\text { de } T \text {. vulgaris não exibiu } \\
\text { atividade antibacteriana. } \\
\text { Bebidas fermentadas de } \\
R \text {. officinalis e } T \text {. vulgaris } \\
\text { não foram ativas contra as } \\
\text { leveduras testadas }\end{array}$ \\
\hline $\begin{array}{l}\text { BHATTACHARYA; } \\
\text { GACHHUI; SIL, } 2013\end{array}$ & Chá preto & $\begin{array}{l}\text { DPPH, eliminação } \\
\text { de radicais } \\
\text { hidroxila e } \\
\text { atividade de } \\
\text { eliminação } \\
\text { de radicais } \\
\text { superóxido }\end{array}$ & $\begin{array}{l}\text { As amostras de chá tiveram potente atividade } \\
\text { de eliminação de radicais livres. A atividade } \\
\text { sequestrante dos radicais DPPH, hidroxila } \\
\text { e superóxido, contudo, foram maiores em } \\
18,9 \%, 17,2 \% \text {, e } 14,97 \% \text {, respectivamente, } \\
\text { nas kombuchas quando comparadas ao chá } \\
\text { preto }\end{array}$ & $\begin{array}{l}\text { A atividade } \\
\text { antimicrobiana não foi } \\
\text { avaliada neste trabalho }\end{array}$ \\
\hline CHU; CHEN, 2006 & Chá preto & DPPH e ABTS & $\begin{array}{l}\text { Das oito amostras comerciais, em quatro } \\
\text { houve aumento da atividade antioxidante } \\
\text { (método DPPH) com o tempo de fermentação. } \\
\text { Para o radical ABTS todas as amostras tiveram } \\
\text { correlação positiva com o aumento do tempo } \\
\text { de fermentação }\end{array}$ & $\begin{array}{l}\text { A atividade } \\
\text { antimicrobiana não foi } \\
\text { avaliada neste trabalho }\end{array}$ \\
\hline $\begin{array}{l}\text { JAYABALAN et al., } \\
2008\end{array}$ & $\begin{array}{l}\text { chá verde, chá } \\
\text { preto e resíduos de } \\
\text { fabricação de chás }\end{array}$ & $\begin{array}{l}\text { DPPH, potencial } \\
\text { de redução, } \\
\text { capacidade } \\
\text { de eliminação } \\
\text { em ânions } \\
\text { superóxido, } \\
\text { habilidade de } \\
\text { eliminação de } \\
\text { radicais hidroxila }\end{array}$ & $\begin{array}{l}\text { Kombuchas preparadas a partir de chá } \\
\text { verde, chá preto e resíduos de fabricação de } \\
\text { chás tiveram altas atividades antioxidantes. } \\
\text { Foi observado aumento da atividade } \\
\text { sequestrante de radicais livres durante a } \\
\text { fermentação }\end{array}$ & $\begin{array}{l}\text { A atividade } \\
\text { antimicrobiana não foi } \\
\text { avaliada neste trabalho }\end{array}$ \\
\hline MALBAŠA et al., 2011 & $\begin{array}{l}\text { Chá verde e chá } \\
\text { preto }\end{array}$ & $\begin{array}{l}\text { Eliminação de } \\
\text { radicais hidroxila, } \\
\text { DPPH }\end{array}$ & $\begin{array}{l}\text { A aplicação de diferentes culturas starters } \\
\text { na elaboração de kombucha proporcionou } \\
\text { diferenças na atividade antioxidante de } \\
\text { ambos substratos }\end{array}$ & $\begin{array}{l}\text { A atividade } \\
\text { antimicrobiana não foi } \\
\text { avaliada neste trabalho }\end{array}$ \\
\hline VITAS et al., 2018 & $\begin{array}{l}\text { Infusão e extrato } \\
\text { aquoso supercrítico } \\
\text { da planta Achillea } \\
\text { millefolium L.). }\end{array}$ & $\begin{array}{l}\text { DPPH, método de } \\
\text { poder de redução, } \\
\text { número de células } \\
\text { viáveis por MTT } \\
\text { (ensaio com 3- } \\
\text { [4,5-dimetiltiazol- } \\
\text { 2-il] -2,5 brometo } \\
\text { de difenil } \\
\text { tetrazólio), MIC }\end{array}$ & $\begin{array}{l}\text { As bebidas de Kombucha produzidas com o } \\
\text { extrato tiveram maior atividade antioxidante } \\
\text { (método DPPH) e maior poder redutor }\end{array}$ & $\begin{array}{l}\text { Todas as bebidas } \\
\text { produzidas exibiram } \\
\text { atividade antimicrobiana. } \\
\text { Kombuchas preparadas } \\
\text { com infusão tiveram } \\
\text { efeito antimicrobiano } \\
\text { mais pronunciado }\end{array}$ \\
\hline SUN; LI; CHEN, 2015 & $\begin{array}{l}\text { Suco de grama } \\
\text { de trigo (Triticum } \\
\text { aestivum L.), chá } \\
\text { preto }\end{array}$ & $\begin{array}{l}\text { DPPH, ABTS } \\
\text { e capacidade } \\
\text { de absorção } \\
\text { de radicais de } \\
\text { oxigênio }\end{array}$ & $\begin{array}{l}\text { O uso do suco de grama de trigo aumentou } \\
\text { a atividade antioxidante medida por DPPH } \\
\text { e capacidade de absorção de radicais de } \\
\text { oxigênio }\end{array}$ & $\begin{array}{l}\text { A atividade } \\
\text { antimicrobiana não foi } \\
\text { avaliada neste trabalho }\end{array}$ \\
\hline $\begin{array}{l}\text { VILLARREAL-SOTO et } \\
\text { al., } 2019\end{array}$ & Chá preto & DPPH & $\begin{array}{l}\text { As frações de butanol, acetato de etila } \\
\text { e aquosa dos kombuchas apresentaram } \\
\text { atividade antioxidante maior que as frações } \\
\text { do chá preto não fermentado }\end{array}$ & $\begin{array}{l}\text { A atividade } \\
\text { antimicrobiana não foi } \\
\text { avaliada neste trabalho }\end{array}$ \\
\hline
\end{tabular}


A kombucha é conhecida principalmente por suas propriedades contra bactérias patogênicas. Essa atividade positiva deve-se aos ácidos orgânicos, como o ácido acético, ácido glucônico, ácido glucurônico, bacteriocinas, proteínas, enzimas e polifenóis do chá, que são produzidos durante o processo fermentativo da kombucha (BHATTACHARYA et al., 2016).

Quanto aos efeitos antimicrobianos observados na revisão, seis artigos apresentaram resultados positivos para os efeitos antimicrobianos. Battikh et al. (2013) reportaram que kombuchas de chá verde e chá preto apresentaram efeito antimicrobiano para as bactérias Bacillus cereus, Salmonella typhimurium, Escherichia coli, Aeromonas hydrophila, Yersinia enterocolitica e Campylobacter jejuni. Esse efeito é resultante dos ácidos orgânicos (particularmente ácido acético e ácido cítrico) e catequinas, os quais são conhecidos por inibirem algumas das bactérias Gram-negativas e Gram-positivas (ANSARI; POURJAFAR; ESMAILPOUR, 2017).

Quanto aos efeitos antimicrobianos relacionados ao tipo de substrato utilizado na produção das kombuchas, dois artigos testaram a atividade antimicrobiana do chá verde contra cepas bacterianas de S. aureus e Salmonella typhimurium (ANSARI; POURJAFAR; ESMAILPOUR, 2017) e contra S. epidermidis, S. aureus, Micrococcus luteus, E. coli, Pseudomonas aeruginosa, $S$. typhimurium e Listeria monocytogenes (BATTIKH et al., 2013).

Os artigos que testaram a atividade antimicrobiana de kombuchas preparadas com chá preto, relataram que os chás reduziram o crescimento das bactérias E. coli O157:H7, Vibrio cholerae, Shigella flexneri 2a, S. Typhimurium, E. coli e S. aureus (BHATTACHARYA et al., 2016). Em outra pesquisa, contudo, o chá preto fermentado não apresentou atividade contra bactérias patogênicas (PURE; PURE, 2016).

Em relação aos substratos não convencionais, kombuchas com suco de uva tiveram maiores efeitos contra S. aureus, Pseudomonas aeruginosa, Klebsiella pneumoniae, E. coli e B. cereus (AYED; BEN ABID; HAMDI, 2017). Já kombuchas de erva-cidreira reduziram o crescimento de bactérias Gram-positivas $S$. equorum, S. saprophyticus e Bacillus sp. (VELIĆANSKI et al., 2014), enquanto kombuchas formuladas com casca de banana e urtiga não apresentaram atividade contra as bactérias E. coli, S. typhimurium, S. aureus, S. saprophyticus, B. stearothermophilus and P. aeroginosa (PURE; PURE, 2016).

Embora as pesquisas sobre atividade antimicrobiana de kombuchas tenham mostrado efeito sobre uma ampla variedade de micro-organismos pato- gênicos, estas também apresentam limitações. Entre essas destaca-se a variabilidade dos resultados no que se diz respeito ao tipo de micro-organismo patogênico que sofrerá esse efeito antimicrobiano. Essa variabilidade está relacionada ao tipo de substrato, como também às concentrações de extrato utilizadas para verificação desse efeito antimicrobiano.

\section{CONCLUSÃO}

Os resultados desta revisão sugerem que as kombuchas preparadas, principalmente com chá preto e chá verde, são capazes de eliminar radicais livres. Essa capacidade já é demonstrada pelos chás não fermentados. $O$ processo de fermentação com as bactérias e leveduras do Scoby usado na elaboração das kombuchas, no entanto, aumentam essa capacidade. Verificou-se, também, resultados positivos para a atividade antimicrobiana em cepas bacterianas patogênicas. Esses resultados podem ser relacionados aos compostos fenólicos produzidos pelos micro-organismos da fermentação.

Além disso, foi observado que substratos provenientes de frutas e plantas são alternativas viáveis para elaboração de kombuchas, tendo atividade antioxidante e antimicrobiana similares e até maiores ao da bebida convencional. Entre esses substratos com melhores propriedades que o chá preto ou chá verde, destacaram-se erva-cidreira, casca de banana e snake fruits.

Assim, o consumo de kombucha consiste em uma alternativa saudável que reduz os níveis de radicais livres e micro-organismos patogênicos.

\section{AGRADECIMENTOS}

Agradecimentos a Coordenação de Aperfeiçoamento de Pessoal de Nível Superior - Brasil (CAPES) Finance Code 001 pelo financiamento.

\section{REFERÊNCIAS}

AMARASINGHE, H.; WEERAKKODY, N. S.; WAISUNDARA, V. Y. Evaluation of physicochemical properties and antioxidant activities of kombucha "Tea Fungus" during extended periods of fermentation. Food Science \& Nutrition, v. 6, n. 3, p. 659-665, May. 2018.

ANSARI, F.; POURJAFAR, H.; ESMAILPOUR, S. Study on Citric Acid Production and Antibacterial Activity of Kombucha Green Tea Beverage during Production and Storage. Annual Research \& Review in Biology, v. 16, n. 3, p. 1-8, 10 Jan. 2017. 
AYED, L.; BEN ABID, S.; HAMDI, M. Development of a beverage from red grape juice fermented with the Kombucha consortium. Annals of Microbiology, v. 67, n. 1, p. 111-121, 26 jan. 2017.

BATTIKH, H. et al. Antibacterial and antifungal activities of black and green kombucha teas. Journal of Food Biochemistry, v. 37, n. 2, p. 231-236, Apr. 2013.

BATTIKH, H.; BAKHROUF, A.; AMMAR, E. Antimicrobial effect of Kombucha analogues. LWT - Food Science and Technology, v. 47, n. 1, p. 71-77, June 2012.

BHATTACHARYA, D. et al. Antibacterial Activity of Polyphenolic Fraction of Kombucha Against Enteric Bacterial Pathogens. Current Microbiology, v. 73, n. 6, p. 885-896, 16 Dec. 2016.

BHATTACHARYA, S.; GACHHUI, R.; SIL, P. C. Effect of Kombucha, a fermented black tea in attenuating oxidative stress mediated tissue damage in alloxan induced diabetic rats. Food and Chemical Toxicology, v. 60, p. 328-340, Oct. 2013.

CHEN, C.; LIU, B. Y. Changes in major components of tea fungus metabolites during prolonged fermentation. Journal of Applied Microbiology, v. 89, n. 5, p. 834-839, Nov. 2000.

$\mathrm{CHU}, \mathrm{S}$. C.; CHEN, C. Effects of origins and fermentation time on the antioxidant activities of kombucha. Food Chemistry, v. 98, n. 3, p. 502-507, 2006.

ESSAWET, N. et al. Polyphenols and antioxidant activities of Kombucha beverage enriched with Coffeeberry ${ }^{\circledR}$ extract. Chemical Industry and Chemical Engineering Quarterly, v. 21, n. 3, p. 399-409, 2014.

FU, C. et al. Antioxidant activities of kombucha prepared from three different substrates and changes in content of probiotics during storage. Food Science and Technology, v. 34, n. 1, p. 123-126, 25 Mar. 2014.

GRAMZA-MICHAŁOWSKA, A. et al. Research on the effect of culture time on the kombucha tea beverage's antiradical capacity and sensory value. Acta Scientiarum Polonorum Technologia Alimentaria, v. 15, n. 4, p. 447-457, 30 Dec. 2016.

JAYABALAN, R. et al. Changes in free-radical scavenging ability of kombucha tea during fermentation. Food Chemistry, v. 109, n. 1, p. 227-234, July 2008.

JAYABALAN, R. et al. A Review on Kombucha Tea-Microbiology, Composition, Fermentation, Beneficial Effects, Toxicity, and Tea Fungus. Comprehensive Reviews in Food Science and Food Safety, v. 13, n. 4, p. 538-550, July 2014.

MALBAŠA, R. V. et al. Influence of starter cultures on the antioxidant activity of kombucha beverage. Food Chemistry, v. 127, n. 4, p. 1.727-1.731, 2011.

PURE, A. E.; PURE, M. E. Antioxidant and Antibacterial Activity of Kombucha Beverages Prepared using Banana Peel, Common Nettles and Black Tea Infusions. Applied Biochemistry and Biotechnology, v. 3, n. 2, p. 125-130, 2016.

RAHMANI, R. et al. Kombucha fermentation of African mustard (Brassica tournefortii) leaves: Chemical composition and bioactivity. Food Bioscience, v. 30, p. 1-9, Aug. 2019.

SANTOS, C.; PIMENTA, C.; NOBRE, M. A estratégia PICO para a construção da pergunta de pesquisa e busca de evidências. Rev. Latino-Am. Enfermagem, v. 15, n. 3, p. 2-5, 2007.
SILVA, Q. C. G. da et al. Risk factors for mediastinitis after coronary artery bypass grafting surgery: An integrative review. Reme: Revista Mineira de Enfermagem, v. 19, n. 4, p. 1.015-1.022, 2015.

SUN, T.-Y.; LI, J.-S.; CHEN, C. Effects of blending wheatgrass juice on enhancing phenolic compounds and antioxidant activities of traditional kombucha beverage. Journal of Food and Drug Analysis, v. 23, n. 4, p. 709-718, Dec. 2015.

VASSÃO, F. V.; MORAES, G. M. De. Revisão integrativa abordagem da sexualidade no cuidado ao paciente oncológico : barreiras e estratégias. Approach to sexuality in the care of cancer patients: barriers and strategies. Acta Paulista de Enfermagem, v. 31, n. 5, p. 564-571, 2018.

VELIĆANSKI, A. S. et al. Antioxidant and Antibacterial Activity of the Beverage Obtained by Fermentation of Sweetened Lemon Balm (Melissa officinalis L.) Tea with Symbiotic Consortium of Bacteria and Yeasts. Food Technology and Biotechnology, v. 52, n. 4, p. 420-429, 23 Dec. 2014.

VILLARREAL-SOTO, S. A. et al. Understanding Kombucha Tea Fermentation: A Review. Journal of Food Science, v. 83, n. 3, p. 580-588, 2018.

VILLARREAL-SOTO, S. A. et al. Impact of fermentation conditions on the production of bioactive compounds with anticancer, anti-inflammatory and antioxidant properties in kombucha tea extracts. Process Biochemistry, n. Oct. 2018, p. 0-1, 2019.

VITAS, J. et al. The antioxidant activity of kombucha fermented milk products with stinging nettle and winter savory. Chemical Industry and Chemical Engineering Quarterly, v. 19, n. 1, p. 129-139, 2013.

VITAS, J. S. et al. Chemical composition and biological activity of novel types of kombucha beverages with yarrow. Journal of Functional Foods, v. 44, n. February 2017, p. 95102, 2018.

WATAWANA, M. I. et al. Health, Wellness, and Safety Aspects of the Consumption of Kombucha. Journal of Chemistry, v. 2.015, p. 1-11, 2015.

WHITTEMORE, R.; KNAFL, K. The integrative review: updated methodology. Journal of Advanced Nursing, v. 52, n. 5, p. 546-553, Dec. 2005.

ZUBAIDAH, E. et al. Comparison of in vivo antidiabetes activity of snake fruit Kombucha, black tea Kombucha and metformin. Biocatalysis and Agricultural Biotechnology, v. 17, n. June 2018, p. 465-469, jan. 2019. 